\title{
EMERGENCY MEDICAL SERVICE PLANNING
}

The paper deals with emergency medical service planning using methods of mathematical programming. The goal is to offer a support tool to the health management evaluating the emergency system quality and efficiency. Mathematical models are implemented in the conditions of the Slovak Republic. Special attention is paid to the Žilina region.

\section{Introduction}

Emergency medical service (EMS) planning includes strategic decisions on the subject of EMS station locations, tactical decisions relating vehicle allocation to the stations as well as operational decisions such as choice of dispatching policy. These decisions have to be based on careful balancing both medical and economic objectives. Quantitative and simulation methods can help in the process of decision making. Quantitative (mathematical) methods are useful at the strategic and perhaps tactical levels of decisions, while simulation methods can help at the tactical and operational levels where a lot of stochastic and unpredictable effects have to be taken into account. The goal of our paper is to present such mathematical and simulation tools.

Emergency medical service (EMS) in the Slovak Republic complies with the Act No 579/2004 Coll. of the National Council of the SR. Regulations of the Ministry of Health of the Slovak Republic No 30/2006 and 365/2006 contain details about EMS including EMS stations deployment. EMS stations are sites where ambulances are located. Further Regulation No 18208/2006 determines EMS providers and type of ambulances at particular stations.

Planning an EMS, the main concern is the response time to calls. The law establishes that the ambulances have to start till 1 minute from obtaining the signal from a dispatching centre. Moreover, there is a recommendation to provide medical care within 15 minutes since the call is received.

In our research, we first evaluated the present ambulance locations from the recommended 15 minutes accessibility point of view. Then using mathematical methods we tried to relocate the stations with the aim to decrease the number of stations while maintaining the service level and to increase the service level while maintaining the number of stations. Input data of our computational experiments include the whole area of the Slovak Republic. More detailed analysis was done on a regional part of Slovakia, specifically on the Žilina region.

\section{Mathematical models}

Many mathematical models for EMS station planning are based on the concept of coverage. In covering models, a maximum value is preset for either distance or travel time. If a service is provided by a facility located within this maximum, then the service is considered acceptable [6]. Then, a customer is considered covered by the service, if he has a facility sited within the preset distance or time. There are two types of objective: we may want to cover all customers with minimum number of facilities or, given a limited number of facilities, to maximize coverage of the population. In the former case, the problem is called a Location Set Covering Problem (LSCP), in the latter case we face a Maximal Covering Location Problem (MCLP).

Following the recommendation of the Ministry of health mentioned in the previous section, the goal of EMS planning in the region of Slovakia is to locate EMS stations in such a way that every municipality is accessible within the time standard of 15 minutes. According to this objective, we can formulate a corresponding LSCP.

It is supposed that potential ambulance locations have been predetermined due to some previous studies. Let us denote the set of location candidates by symbol $J$. Its elements are indexed by symbol $j$. Further, $I$ states for the set of all municipalities in the region under consideration and $i$ denotes a particular municipality. Both sets $I$ and $J$ correspond to nodes of a road network $N_{i}<J$. is the set of potential locations which can cover municipality $i$. Bivalent variable $x_{j} \in[0,1]$ models the decision if a station is located at node $j\left(x_{j}=1\right)$ or not $\left(x_{j}=0\right)$. The formulation of the model is as follows:

$$
\begin{array}{lll}
\text { minimize } & Z=\sum_{j \in J} x_{j} & \\
\text { subject to } & \sum_{j \in N_{i}} x_{j} \geq 1 & \forall i \in I \\
& x_{j} \in[0,1] & \forall j \in J
\end{array}
$$

* doc. Ing. L’udmila Jánošíková, CSc.

University of Žilina, Faculty of Management Science and Informatics, Department of Transport Networks, E-mail: Ludmila.Janosikova@fri.utc.sk 
The objective (1) minimizes the number of stations required. Constraints (2) state that each municipality $i$ must be covered by at least one station within the time standard.

The solution of this model, i.e. mandatory coverage of all people no matter how far they live, may require excessive resources. Limited budget is respected in the second basic covering model, the Maximal Covering Location Problem (MCLP). Instead of full coverage of all demands, this model seeks the location of a fixed number of facilities in such a way that population covered by the service is maximized.

Let us introduce the additional notation: $a_{i}$ is the population of municipality $i$ and $p$ is the predefined number of stations to be deployed. The coverage of node $i$ is conditional and depends on if a station is located in its set $N_{i}$. This is modelled by decision variables $y_{i} \in\{0,1\}$. Variable $y_{i}$ takes value 1 if at least one station is located within the time standard, otherwise $y_{i}=0$. The integer programming formulation of the problem is the following:

$$
\begin{array}{lll}
\text { maximize } & Z=\sum_{i \in I} a_{i} y_{i} & \\
\text { subject to } & \sum_{j \in N_{i}} x_{j} \geq y_{i} & \forall i \in I \\
& \sum_{j \in J} x_{j}=p & \\
& x_{j}, y_{i} \in\{0,1\} & \forall i \in I, j \in J
\end{array}
$$

Church and ReVelle [3] presented several other model forms of MCLP. They proved that locating a set of facilities to maximize coverage is equivalent to locating a set of facilities that minimize the amount of demand left uncovered. The problem minimizing uncovered population is a $p$-median problem, which can be transformed using Lagrangean relaxation to the uncapacitated location problem [5].

As usually only one ambulance operates at each station, this station can not respond to calls if the ambulance is occupied. In this case the call is dispatched to a backup station. It is desired the backup station to be located within the time standard, too. Thus we can formulate a more comprehensive model seeking redundancy in coverage. According to Hogan and ReVelle [4], the model is as follows:

$$
\begin{array}{lll}
\text { maximize } & Z=\sum_{i \in I} a_{i} y_{i}+\sum_{i \in I} a_{i} r_{i} & \\
\text { subject to } & \sum_{j \in N_{i}} x_{j} \geq y_{i}+r_{i} & \forall i \in I \\
& r_{i} \leq y_{i} & \\
& \sum_{j \in J} x_{j}=p & \\
& x_{j}, y_{i}, r_{i} \in\{0,1\} & \forall i \in I, j \in J
\end{array}
$$

where $r_{i}=1$ if a second station is sited within the time standard of node $i$. The objective maximizes first and second coverages. Constraints (9) say that the coverage by a first and second station is not possible unless at least two stations are initially located in the neighbourhood of node $i$. Constraints (10) reflect the fact that the backup coverage cannot be fulfilled without the first coverage. Constraint (11) limits the number of stations to be deployed.

The solutions of all the models mentioned so far determine how many stations and where need to be built up. They do not decide the number of vehicles to be placed at each station. These tactical decisions require more detailed modelling.

On strategic decisions level, details about system performance are not taken into account and in many cases they are not known in the moment. The definition of coverage itself is based on an implicit assumption that there is always an available ambulance to respond to a call. But in a real system this may not be true, even in the case of backup coverage, because calls arriving are stochastic events. Moreover, the models mentioned above do not reflect dynamically changing conditions. For example, deterministic travel time from the demand node $i$ to a candidate location is used to compute covering set $N_{i}$. This travel time depends only on the distance and the average speed for a given road type. But in the real world, traffic volume and weather conditions have also impact on the travel time. Because of variable and stochastic conditions, the required system performance cannot be guaranteed in practice.

Probabilistic mathematical models provide a more realistic and more detailed system design including decisions about the number of ambulances at each station. Here, both the probability of ambulance availability and the probability that the call is responded in the time standard are incorporated. Before computing these probabilities it is important to know the operation of emergency system, particularly what happens after the emergency call arrives.

The attendance of a call consists of the following operations:

1. pre-travel handling of the call (a dispatcher has to obtain the address and establish the seriousness of the call, decide which ambulance to dispatch and contact the crew of that ambulance, then the crew have to reach the ambulance and start it);

2. movement of the ambulance from the station to the demand location;

3. treatment of the patient by the ambulance crew;

4. transport of the patient to the nearest hospital;

5. passing the patient to the hospital staff;

6. movement of the ambulance back to the station.

Response time is determined by the first two operations. The probability of response time being in the predefined limit can be modelled if the travel time between all pairs (station, demand node) is known and, perhaps, the probability distribution for pre-trip delays is known (see, for example, Ingolfsson in [2]). The probability of the ambulance availability stems from estimation of the fraction of time during which the ambulance is busy. The shortcoming of this approach is that it is not possible to determine the busy time of the ambulances before knowing the final location of all of them. Therefore, in our opinion, probabilistic models are not suitable for allocation of ambulances especially in a rural area, where busy times may vary a lot in dependence on travel times. In this case, 
simulation seems to be the best way to support tactical and operational decisions and to get an idea about system performance under real conditions.

\section{Simulation model}

Simulation should give answers to two basic questions:

1. what is real coverage, i.e. what percent of calls is responded within the time standard (evaluated particularly for every municipality, as well as for the whole region);

2. what is the ambulance efficiency (the busy fractions of the ambulances).

These evaluations should result into arrangements improving system performance such as allocating more ambulances to a station. This decision can be implemented in practice in such a way that more stations with one ambulance will be deployed in the city area.

Simulating the EMS system, it can be viewed as a queuing system with a Poisson process of arrival events and exponentially distributed service time. Every municipality has its own arrival rate $\lambda_{i}$ (calls per time unit). Because statistical data relating the number of calls from particular municipalities are not published, we can use a summary statistics for the Slovak Republic for year 2001 [8] reporting the number of EMS patients was 232,904 and the population was $5,379,455$. Then the rate per one inhabitant $\lambda$ can be calculated and used for estimation of $\lambda_{i}=\lambda a_{i}$, where $a_{i}$ is the number of inhabitants of municipality $i$.

Modelling the service time (step 3 to 6 of call attendance), we can use deterministic travel times, a constant time spent remaining at a hospital and an exponential treatment time with the mean service time $1 / \mu$.

There are several dispatching policies how to allocate a call to a station. The call is always allocated to the nearest station and policies differ in a situation when the nearest ambulance is busy. The call can wait until the ambulance returns back to the station or it can be reallocated to the next nearest station with an idle ambulance. A simulation model allows to experiment with dispatching policies and consequently to choose the best one.

\section{Experiments with models}

In our experiments, we aimed our attention to the whole area of the Slovak Republic and in a more detailed manner to the Žilina region. First, we analysed the present situation and then we solved the above mentioned location models to determine the optimal number and deployment of ambulance stations according to a specific criterion.

We omitted pre-travel delays. If we had real data, a mean value of pre-travel delay could be evaluated and added to travel times to achieve more realistic response times in mathematical models. So, in our experiments, the response time consists only of travel time between the station and the place of incident. The travel time is deterministic and depends on the distance and the average speed that we supposed to be for a given road type as follows:

- highway - $105 \mathrm{~km} / \mathrm{h}$,

- important main road - $95 \mathrm{~km} / \mathrm{h}$,

- main road $-75 \mathrm{~km} / \mathrm{h}$,

- secondary road $-60 \mathrm{~km} / \mathrm{h}$,

- $\operatorname{minor}$ road $-50 \mathrm{~km} / \mathrm{h}$.

Nowadays, there are 264 EMS stations in the Slovak Republic placed in 206 cities and serving 2916 municipalities. Under assumption of the mentioned travel speeds, there are 95 municipalities inaccessible from these stations within the 15 minutes limit, which means that the coverage is $99.33 \%$ of population.

Before formulating mathematical models, the set of candidate station locations needs to be determined. The set of candidate station locations consists of present stations locations plus municipalities with at least 2000 inhabitants as proposed by Janáček [5]. There are 466 cities meeting these conditions. 72 municipalities are inaccessible from any candidate location. Therefore, the initial coverage matrix in conditions (3) of the LSCP model has 2844 rows and 466 columns. Applying reduction rules according to [7], the coverage matrix is reduced to 196 rows and 322 columns. After coverage matrix reduction, the LSCP model was solved using commercial linear-integer programming software XPRESS. The optimal solution consists of 159 stations.

The present situation in the Žilina region is shown in Fig. 1. In the figure, deployment of 28 stations is plotted and time accessibility of municipalities is expressed in colour. Multiple stations in one city are aggregated to one location without substantial impact on the availability. We can see that the goal of 15 minutes accessibility is almost reached. Only three small villages (Čičmany, Kalamenová and Vrícko) are not accessible within the 15 minutes limit.

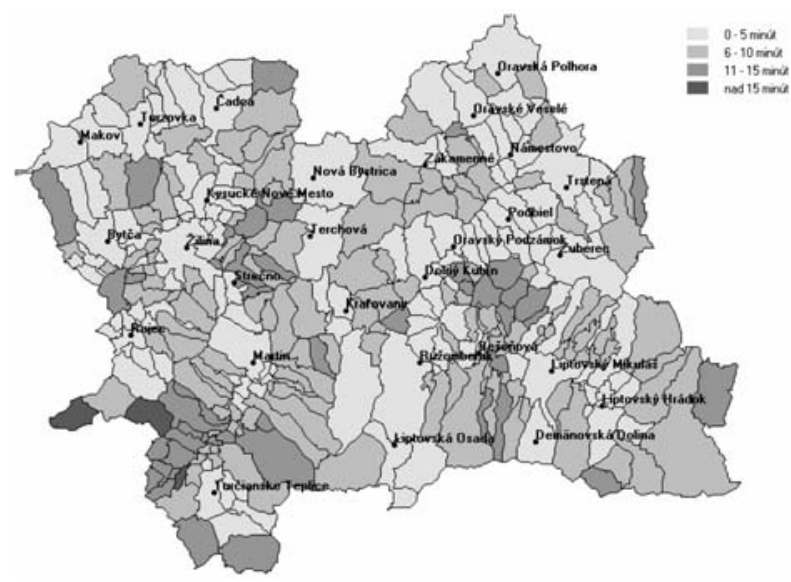

Fig. 1 Time accessibility at present ambulance locations 
In the next step, the appropriate LSCP and the backup MCLP can be formulated for the Žilina region. The set of candidate locations consists of 73 municipalities. Three villages inaccessible nowadays cannot be reached from any of these candidates within the 15 minutes limit and that is why they are excluded from the models.

The shortcoming of the LSCP as well as MCLP models is that a station need not be located in a major city (with large demand, a hospital etc.) but it can be placed in a small village nearby (if the village is a candidate location, of course). Therefore, it is reasonable to prescribe the value 1 for variables $x j$ that represent large cities with a hospital (Čadca, Dolný Kubín, Liptovský Mikuláš, Martin, Ružomberok, Trstená, and Žilina in the Žilina region).

The solution of the LSCP model is presented in Fig. 2. There can be seen that only 22 stations are placed in the region.

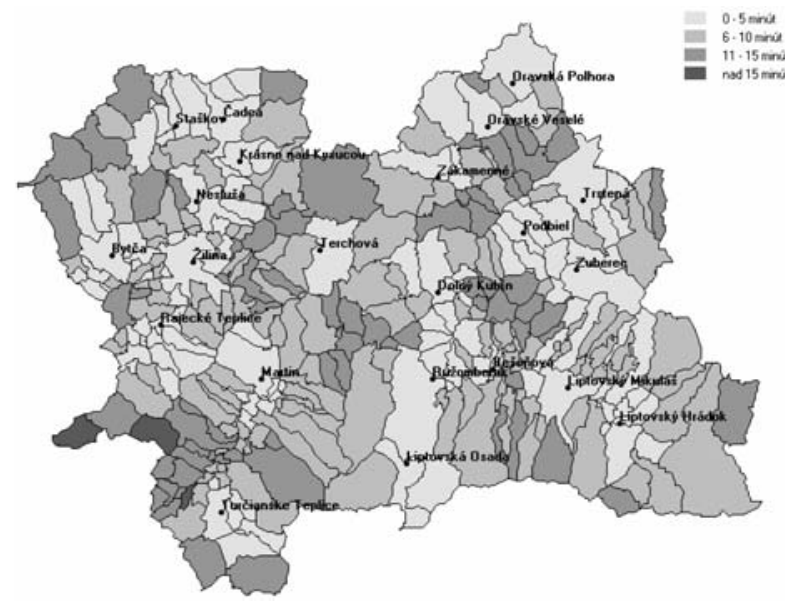

Fig. 2 Solution of the LSCP

Consequently, the backup MCLP was solved under the assumption that no more than 22 stations need to be deployed in the region. Statistical comparison of the present state, the LSCP solution and the backup MCLP solution are presented in Table 1. Comparing the MCLP and LSCP solutions, we can agree with the

Comparison of the solutions

\begin{tabular}{|c|c|c|c|c|}
\hline & & $\begin{array}{c}\text { present } \\
\text { state }\end{array}$ & LSCP & $\begin{array}{l}\text { backup } \\
\text { MCLP }\end{array}$ \\
\hline $\begin{array}{l}\text { Uncovered } \\
\text { municipalities }\end{array}$ & $\begin{array}{l}\text { Count } \\
\text { Percent of } \\
\text { population }\end{array}$ & $\begin{array}{c}3 \\
0.10\end{array}$ & $\begin{array}{c}3 \\
0.10\end{array}$ & $\begin{array}{c}10 \\
1.48\end{array}$ \\
\hline $\begin{array}{l}\text { Municipalities } \\
\text { covered by } \\
1 \text { station }\end{array}$ & $\begin{array}{l}\text { Count } \\
\text { Percent of } \\
\text { population }\end{array}$ & $\begin{array}{c}60 \\
10.00\end{array}$ & $\begin{array}{c}107 \\
29.59\end{array}$ & $\begin{array}{l}59 \\
8.53\end{array}$ \\
\hline $\begin{array}{l}\text { Municipalities } \\
\text { covered by at } \\
\text { least } 2 \text { station }\end{array}$ & $\begin{array}{l}\text { Count } \\
\text { Percent of } \\
\text { population }\end{array}$ & $\begin{array}{r}252 \\
89.90\end{array}$ & $\begin{array}{c}205 \\
70.30\end{array}$ & $\begin{array}{r}246 \\
89.99\end{array}$ \\
\hline
\end{tabular}

observations of Hogan and ReVelle [4] that marginal reductions in the first coverage improve strongly the backup coverage. The reasoning is that the fraction of the uncovered population increased by $1.38 \%$ in the backup design, while the fraction of population covered by at least two stations increased by $19.69 \%$.

Emergency calls can occur not only in municipalities, but also on roads in consequence of traffic accidents. Therefore, it is reasonable to require the road segments where many traffic accidents happen to be covered by emergency medical service as well. These road segments are called black spots. They are evaluated by Slovak Road Administration every year [1]. As their length is up to 500 meters, they can be modelled as points on the road network. Black spots in the Žilina region in year 2004 are shown in Fig. 3.

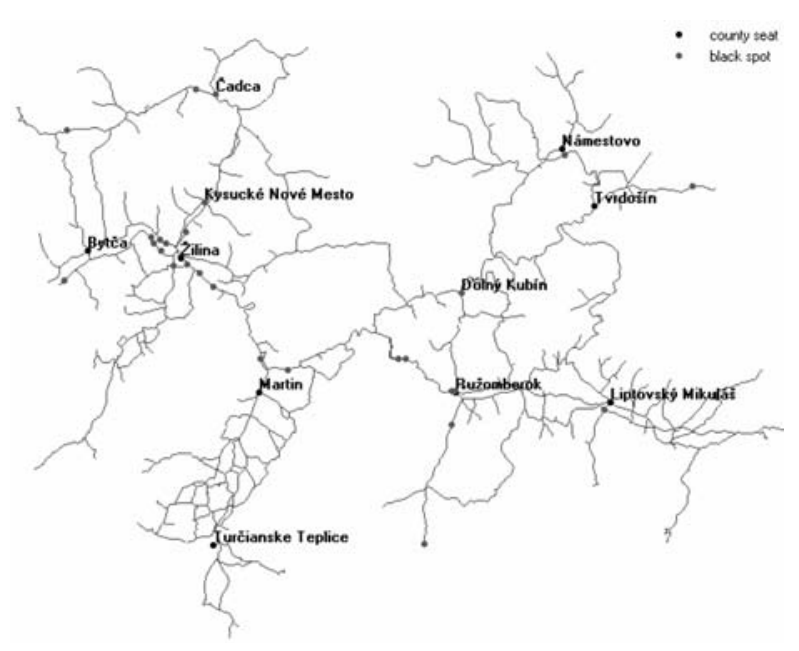

Fig. 3 Black spots on the road network in the Žilina region in year 2004

Mathematical and simulation models can be modified to incorporate black spots. In the LSCP model, inequalities of the form (2) are added for black spots. In the case of the Žilina region, black spots did not affect the optimal solution of the LSCP.

In the MCLP models, new bivalent variables $y_{i}$ and $r_{i}$ for every black spot are introduced. Objective functions (4) and (8), respectively are supplemented by these variables and inequalities of the form (5), (9) and (10) are added to the models. Coefficients $a_{i}$ for black spots can represent traffic flow rates for the given road segments.

Simulating EMS system performance, black spots are modelled as demand points with the arrival rate equal to the number of traffic accidents per year.

\section{Conclusion}

We have presented the application of three known mathematical programming models for EMS station location and their 
enhancement by road segments with many traffic accidents. Based on these models, a decision support software tool has been developed. This tool enables to change input parameters of the problem including a region, travel speeds, criterion for candidate locations and a time limit for coverage. The solutions of the models are displayed in a graphical form and saved in text files for a subsequent analysis.

In addition to mathematical models, a simulation model has been developed and some preliminary simulation experiments have been done.
We believe that this support tool can be useful for health management evaluating the present EMS system in terms of those parameters which can be figured out and designing a better solution.

\section{Acknowledgement}

This paper was supported by grant VEGA 1/3775/06

\section{References}

[1] Traffic accident rate in network of roads of SR in 2004 year [online], Slovenská správa ciest, 11/2006 [cit. 2006-11-10], http://www.ssc.sk

[2] BUDGE, S., ERKUT, E., INGOLFSSON, A.: Optimal Ambulance Location with Random Delays and Travel Times, Working paper, University of Alberta School of Business, 2005.

[3] CHURCH, R. REVELlE, C.: The Maximal Covering Location Problem, Papers of the Regional Science Association, 32/1974, p.p. 101-118.

[4] HOGAN, K., REVELLE, C.: Concepts and applications of backup coverage, Management Science, ISSN 0025-1909, 11/1986, p.p. 1434-1444.

[5] JANÁČEK, J.: The medical emergency service system design, Mikulski, J. (editor) Advances in Transport Systems Telematics, Katowice: Jacek Skalmierski Computer Studio, 2006, ISBN 83-917156-4-7.

[6] MARIANOV, V., SERRA, D.: Location problems in the public sector, Drezner, Z., Hamacher, H. W. (editors) Facility Location: Applications and Theory, 1st ed. Heidelberg: Springer-Verlag Berlin, 2004, ISBN 3-540-21345-7.

[7] TOREGAS, C., REVELLE, C.: Binary logic solutions to a class of location problems, Geographical Analysis, 5/1973, p.p. 145-155.

[7] Prezentácia ZZS SR [online], Záchranná služba Košice, 11/2006 [cit. 2006-11-30], http://www.kezachranka.sk 